\title{
ChemPlusChem
}

DOI: 10.1002/cplu.201((will be completed by the editorial staff))

\section{Aerosol Assisted Chemical Vapour Deposition of Transparent Zinc Gallate Films}

\author{
Caroline E. Knapp, Joe A. Manzi, Andreas Kafizas, Ivan P. Parkin and Claire J. Carmalt*
}

Aerosol assisted chemical vapour deposition (AACVD) reactions of $\mathrm{GaMe}_{3}, \mathrm{ZnEt}_{2}$, and 6 equivalents of the donor functionalized alcohol, $\mathrm{HOCH}_{2} \mathrm{CH}_{2} \mathrm{OMe}$, in toluene resulted in the deposition of amorphous transparent zinc gallate $\left(\mathrm{ZnGa}_{2} \mathrm{O}_{4}\right)$ films at a range of temperatures $\left(350-450{ }^{\circ} \mathrm{C}\right)$. The zinc-gallium-oxide films were analyzed by scanning electron microscopy (SEM), X-ray photoelectron spectroscopy (XPS), energy dispersive X-ray analysis (EDX), glancing-angle $\mathrm{X}$-ray powder diffraction $(\mathrm{XRD})$ and optical studies.

\section{Introduction}

In recent years there has been a surge in the development of catalysts to be used in the field of photoelectrical water splitting, since these methods often offer clean and efficient alternatives to generating electricity. ${ }^{[1-4]}$ The world's energy demands are ever increasing; it is not just essential to find renewable energy alternatives but also to improve processes that will stabilize atmospheric $\mathrm{CO}_{2}$ levels. The current rates of water splitting are low, and whilst the conversion of sunlight into fuel via water splitting is a known technology, there is much research into improving this area. ${ }^{[1]}$

$\mathrm{ZnGa}_{2} \mathrm{O}_{4}$ has seen much discussion in the last decade owing to its potential application in water splitting, ${ }^{[1]}$ degradation of pollutants, ${ }^{[2]}$ photoreduction of $\mathrm{CO}_{2}{ }^{[3]}$ and as reflective optical coatings in the aerospace industry. ${ }^{[4]}$ It is well reported both in experimental and theoretical investigations that photocatalysis of zinc gallate has been used extensively in photoelectrochemical water splitting, ${ }^{[5]}$ dye sensitized solar cells, ${ }^{[6]}$ and various other applications. ${ }^{[7,8]}$

The adsorption and subsequent decomposition of water on $\mathrm{ZnGa}_{2} \mathrm{O}_{4}$ has been investigated previously, and a DFT study showed that water adsorption and decomposition were surface structure dependent. ${ }^{[9]}$ Further afield these materials, when doped, have application as phosphors. ${ }^{[32]} \mathrm{ZnGa}_{2} \mathrm{O}_{4}$ crystalizes in the space group $\mathrm{Fd} 3 \mathrm{~m}$, with a close packed face centered cubic structure. ${ }^{[10]}$ The $\mathrm{Ga}^{3+}$ ion occupies the octahedrally coordinated sites, whilst $\mathrm{Zn}^{2+}$ occupies the tetrahedral sites. ${ }^{[11]}$

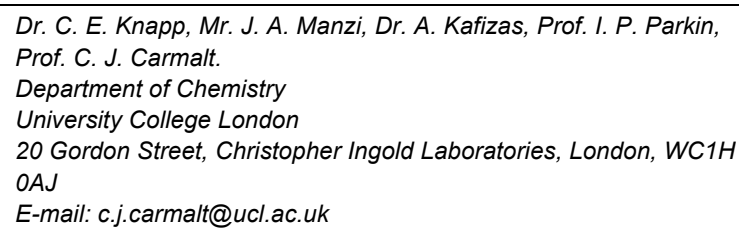

The optimum growth temperature was found to be $450{ }^{\circ} \mathrm{C}$, which produced transparent films with excellent coverage of the substrate. XPS confirmed the presence of zinc, gallium and oxygen in the films. Annealing these films at $1000{ }^{\circ} \mathrm{C}$ resulted in crystalline films and glancing-angle powder XRD showed that a zinc gallate spinel framework with a lattice parameter, $a=8.336(5) \AA$, was adopted.

Luminescence of $\mathrm{ZnGa}_{2} \mathrm{O}_{4}: \mathrm{Cr}^{3+}$ has shown a vast improvement when substituting the traditional chromium or manganese dopant to a germanium or tin dopant. The synthetic methods employed to isolate these spinel solid solutions often include multi step synthesis, requiring high temperatures over several days. Moreover the optical properties of zinc gallate depend on the synthetic conditions. A wide range of methods have been employed, including thermal vaporization, sol gel and highfrequency RF ion plasma sputtering methods (for thin films) and hydrothermal and glycothermal (for solids). ${ }^{[12,13]}$

Whilst traditional spinel synthesis is a laborious process, with the synthesis of $\mathrm{ZnGa}_{2} \mathrm{O}_{4}$ spinel including lengthy experimental procedures and high temperatures $\left(1200{ }^{\circ} \mathrm{C}\right)^{[15]}$ chemical vapour deposition (CVD) is a viable alternative that has been used recently for the synthesis for $\mathrm{CuGa}_{2} \mathrm{O}_{4} \cdot{ }^{[17]} \mathrm{CVD}$ is usually limited simply by precursor requirements, for example volatility in atmospheric pressure (AP)CVD, or solubility in aerosol assisted (AA)CVD. The range of potentially applicable precursors is vast, and the solution based precursors, formed in situ, used in this report are well reported. ${ }^{[16]}$

In addition, AACVD allows for control of film morphology and composition suggesting that selective growth of surfaces is possible. We have previously investigated CVD methods for the deposition of transparent conducting oxides (TCOs), photocatalysts and gas sensors: ${ }^{[18]}$ including $\mathrm{Ga}_{2} \mathrm{O}_{3},{ }^{[19-25]}$, $\ln _{2} \mathrm{O}_{3},{ }^{[26,27]}, \quad \mathrm{Ga}_{x} \ln _{2-\mathrm{x}} \mathrm{O}_{3}{ }^{[28,29]}, \quad \ln _{2} \mathrm{O}_{3}: \mathrm{Ti}, \quad \ln _{2} \mathrm{O}_{3}: \mathrm{Ta}^{[30]}$ and $\mathrm{TiO}_{2}: \mathrm{SnO}_{2}{ }^{[31]}$

In this contribution we describe the use of readily available chemicals for the deposition of zinc gallate via AACVD. Herein we report a novel synthetic route to $\mathrm{ZnGa}_{2} \mathrm{O}_{4}$ thin films on glass.

\section{Results and Discussion}

The AACVD reaction of $\mathrm{GaMe}_{3}, \mathrm{ZnEt}_{2}$ and the donor functionalised alcohol $\mathrm{HOCH}_{2} \mathrm{CH}_{2} \mathrm{OMe}$ on glass and quartz 


\section{ChemPlusChem}

\section{Full Papers \\ www.chempluschem.org}

substrates was studied between $350-550{ }^{\circ} \mathrm{C}$, according to Scheme 1. For each system, deposition was observed on both the substrate and top plate. The top plate was measured to be ca. $50-70{ }^{\circ} \mathrm{C}$ lower in temperature than the substrate. Films deposited on the substrate were used in all analysis. At all deposition temperatures the films showed good substrate coverage, were transparent and strongly adherent (passed the Scotch $^{\mathrm{TM}}$ tape test but could be scratched off with a steel scalpel). The resulting films in all instances were found to be thin (ca. $300 \mathrm{~nm}$ ), of uniform thickness and at $450{ }^{\circ} \mathrm{C}$ were deposited across the full length of the substrate. The deposited films were insoluble in common organic solvents, but quickly decomposed in nitric acid. Additionally four-point probe measurements suggest that the films were not electrically conductive at room temperature. Unlike most films prepared via AACVD pre-annealed films did not exhibit a brown tint, indicative of carbon contamination in the films, suggesting that this approach to these thin films limits carbon incorporation.

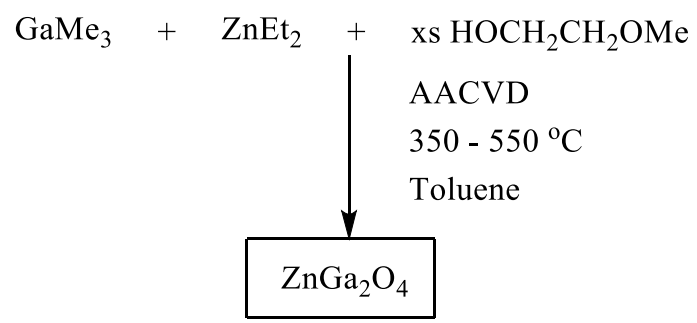

Scheme 1. Aerosol-assisted chemical vapour deposition of $\mathrm{GaMe}_{3}, \mathrm{ZnEt}_{2}$ and $\mathrm{HOCH}_{2} \mathrm{CH}_{2} \mathrm{OMe}$ in toluene.

The reaction of $\mathrm{GaMe}_{3}, \mathrm{ZnEt}_{3}$ and excess $\mathrm{ROH}$ ( $\mathrm{R}=$ $\mathrm{CH}_{2} \mathrm{CH}_{2} \mathrm{OMe}$ ) in toluene was assumed to generate in situ organoalkoxometallanes, such as $\left[\mathrm{Me}_{2} \mathrm{Ga}(\mu-\mathrm{OR})_{2} \mathrm{ZnEt}\right]$, or mixtures of $\left[\mathrm{Me}_{2} \mathrm{Ga}(\mu-\mathrm{OR})_{2}\right]$ and $[\mathrm{MeZn}(\mathrm{OR})]$ which would have similar structures to compounds synthesized in solution based reactions described previously. ${ }^{[36-39]}$ The deposition conditions and analysis of the films grown are given in Table 1.

Table 1. Deposition conditions and analysis of the films grown from the AACVD of $\mathrm{GaMe}_{3}, \mathrm{ZnEt}_{2}$ and $\mathrm{HOCH}_{2} \mathrm{CH}_{2} \mathrm{OMe}$ in toluene.

\begin{tabular}{|llll|}
$\begin{array}{l}\mathrm{GaMe}_{3}: \mathrm{ZnEt}{ }_{2} \\
\text { in bubbler }\end{array}$ & $\begin{array}{l}\text { Temperature of } \\
\text { deposition }\left({ }^{\circ} \mathrm{C}\right)\end{array}$ & Surface & EDXA \\
\hline $1: 1$ & 350 & Film & $\mathrm{Zn}_{1.4} \mathrm{Ga}$ \\
\hline $1: 1$ & 450 & Film & $\mathrm{ZnGa}_{2.6}$ \\
\hline $1: 1$ & 450 & Feature & $\mathrm{ZnGa}_{2.6}$ \\
\hline $1: 1$ & 550 & Film & $\mathrm{ZnGa}_{2.9}$ \\
\hline $1: 1$ & 550 & Feature & $\mathrm{ZnGa}_{3}$ \\
\hline
\end{tabular}

The gallium-zinc-oxide films were characterized using a range of techniques. Glancing-angle X-ray diffraction (XRD) showed films deposited by AAVCD were amorphous at all deposition temperatures as expected since crystalline films of $\mathrm{ZnGa}_{2} \mathrm{O}_{4}$ are typically deposited at temperatures $>625{ }^{\circ} \mathrm{C}$. ${ }^{[33-38]}$ With particular relevance to this study, we have previously described the AACVD of $\mathrm{GaMe}_{3}, \operatorname{InMe}_{3}$ and $\mathrm{HOCH}_{2} \mathrm{CH}_{2} \mathrm{OMe}$, which resulted in the formation of amorphous thin films of gallium-indium-oxide, which on annealing at $1000{ }^{\circ} \mathrm{C}$ resulted in highly transparent $\mathrm{Ga}_{0.4} \mathrm{In}_{1.6} \mathrm{O}_{3}$ films. ${ }^{[28,29]}$ Films deposited at $450{ }^{\circ} \mathrm{C}$ showed the best coverage of the substrate, with a complete conformal coating and so were also deposited on quartz substrates. These films were subsequently annealed at $1000{ }^{\circ} \mathrm{C}$, which resulted in highly transparent films and glancing-angle XRD showed that the spinel, $\mathrm{ZnGa}_{2} \mathrm{O}_{4}$ had formed (Figure 1). The broad peak between $15^{\circ}$ and $30^{\circ}$ is a feature of the silica substrate, often observed in glancing angle $X R D$, particularly with thin films. Interestingly, annealing had no effect on the morphology of the films, although this could be a result of the film thickness. It has previously been reported that crystalline $\mathrm{ZnGa}_{2} \mathrm{O}_{4}$ films are deposited at temperatures above $625{ }^{\circ} \mathrm{C}$, but that annealing above $650{ }^{\circ} \mathrm{C}$ results in the

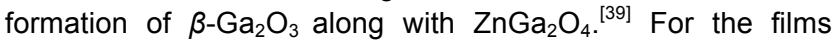
described herein and annealed at $1000{ }^{\circ} \mathrm{C}$, crystalline $\beta-\mathrm{Ga}_{2} \mathrm{O}_{3}$ was not detected by $\mathrm{XRD}$, only single phase $\mathrm{ZnGa}_{2} \mathrm{O}_{4}$. This could be due to the polycrystalline nature of the material, as evident in the XRD.

The lattice parameter of the material was deduced via a La Bail refinement to be 8.336(5) $\AA$ and all peaks were indexed to the cubic spinel $\mathrm{ZnGa}_{2} \mathrm{O}_{4}$ phase. The lattice parameter matches well with previous literature reports for thin films of $\mathrm{ZnGa}_{2} \mathrm{O}_{4}(8.3342(5) \AA) .{ }^{[34-36,40,41]}$ The most intense peak for the zinc gallate (Figure 1$)$ corresponds to the $\left(\begin{array}{lll}3 & 1 & 1\end{array}\right)$ plane. No peaks were observed for separate phases of zinc oxide, gallium oxide or gallium-doped zinc oxide in the XRD pattern.

In gallium-doped zinc oxide ( $\mathrm{ZnO}: \mathrm{Ga}$ ), only small lattice distortions are expected due to the similar ionic radii of $\mathrm{Zn}^{2+}$ and $\mathrm{Ga}^{3+}$. However, gallium doping can also result in the formation of spinel structures $\left(\mathrm{M}^{\prime \prime} \mathrm{Ga}_{2} \mathrm{O}_{4}\right)$, particularly when the matrix to be doped is $\mathrm{ZnO}$ and heavily doped samples are formed. In the normal spinel structure of $\mathrm{ZnGa}_{2} \mathrm{O}_{4}$, the $\mathrm{Zn}^{2+}$ ions occupy tetrahedral sites and $\mathrm{Ga}^{3+}$ ions the octahedral ones. A previous report describing the deposition of galliumdoped zinc oxide or spinel $\mathrm{ZnGa}_{2} \mathrm{O}_{4}$ via the plasma-enhanced CVD of $\mathrm{ZnEt}_{2}$ and $\mathrm{GaMe}_{3}$ in an oxygen plasma found that the ratio of the organometallic precursors had a significant effect on the phase obtained. ${ }^{[4]}$ Films deposited when the gallium fraction was $\geq 50 \%$ resulted in insulating films that adopted the $\mathrm{ZnGa}_{2} \mathrm{O}_{4}$ spinel structure, whereas $\leq 40 \%$ gallium precursor yielded conductive gallium-doped zinc oxide. It is therefore likely that the ratio of the organometallic precursors used in the AACVD experiments $\left(\sim 1: 1 \quad \mathrm{ZnEt}_{2}: \mathrm{GaMe}_{3}\right)$ had a significant impact on the phase of material produced with the relatively high gallium addition affording $\mathrm{ZnGa}_{2} \mathrm{O}_{4}$ films. 


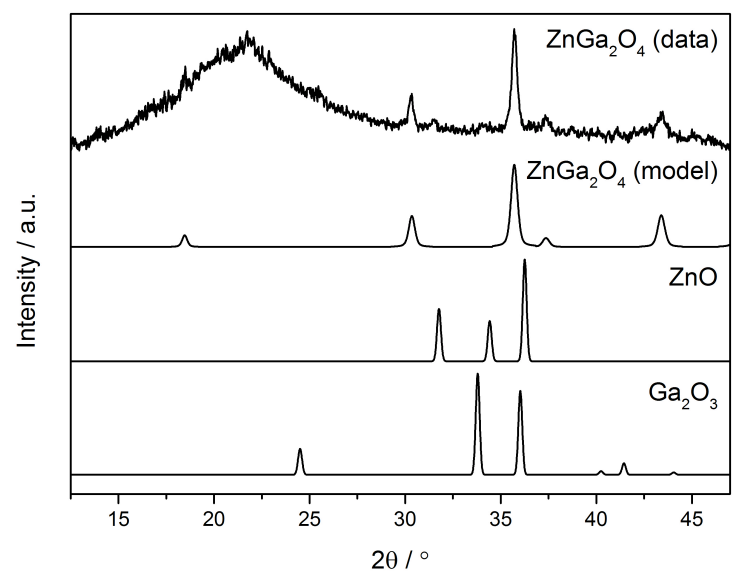

Figure 1. XRD of a film of $\mathrm{ZnGa}_{2} \mathrm{O}_{4}$, deposited on quartz at $450{ }^{\circ} \mathrm{C}$ and annealed at $1000{ }^{\circ} \mathrm{C}$, a generated model of $\mathrm{ZnGa}_{2} \mathrm{O}_{4}$, and for comparison, standards for $\mathrm{ZnO}$ and $\mathrm{Ga}_{2} \mathrm{O}_{3}$.

Energy dispersive $\mathrm{X}$-ray analysis (EDXA) confirmed the presence of gallium, zinc and oxygen, however breakthrough to the underlying glass substrate was observed in all instances as the films were thin and therefore the metal to oxygen ratios could not be accurately deduced. No carbon was detected in EDXA experiments so carbon contamination levels as a direct result of the precursors and solvents used were suitably low (typically 1 at. $\%$ detection level).

Films grown at $450{ }^{\circ} \mathrm{C}$ and annealed at $1000{ }^{\circ} \mathrm{C}$ were found to have a $\mathrm{Zn}$ to $\mathrm{Ga}$ ratio of 1:2.6 from EDXA. The observed $\mathrm{Zn}: \mathrm{Ga}$ ratio by EDXA was consistent in all areas of the film and suggests the possible formation of the spinel oxide $\mathrm{ZnGa}_{2} \mathrm{O}_{4}(\mathrm{Zn:Ga} 1: 2)$ along with a secondary phase, which is likely to be $\mathrm{Ga}_{2} \mathrm{O}_{3}$, accounting for the presence of excess gallium. The formation of $\mathrm{ZnGa}_{2} \mathrm{O}_{4}$ is consistent with the XRD data and the proposed presence of $\mathrm{Ga}_{2} \mathrm{O}_{3}$ corresponds with previous reports where higher temperatures yielded crystalline $\mathrm{ZnGa}_{2} \mathrm{O}_{4}$ along with amorphous $\mathrm{Ga}_{2} \mathrm{O}_{3} .{ }^{[42]}$

Films grown at $350{ }^{\circ} \mathrm{C}$ were the only instance where the zinc content was higher than the gallium, with a $\mathrm{Zn}$ to $\mathrm{Ga}$ ratio of $1.4: 1$, however coverage of the substrate was poor, suggesting low temperature results in incomplete deposition. Films grown at $550{ }^{\circ} \mathrm{C}$ and annealed at $1000{ }^{\circ} \mathrm{C}$ showed the lowest $\mathrm{Zn}$ content, with ratios of $\mathrm{Zn}$ to $\mathrm{Ga}$, in all areas of the film, being 1:3.0. The increase in the zinc to gallium ratio with increase in substrate deposition temperature can be assigned in part to the volatility of the precursors used. $\mathrm{ZnEt}_{2}$ is less volatile than $\mathrm{GaMe}_{3}$, which would, in turn, oxidize more readily, particularly at higher temperatures.

At all deposition temperatures films were smooth, transparent, and had no detectable carbon content. The films are featureless, but after scanning large areas of the films at fairly low magnification $(\times 900)$ a few surface defects can be found (Fig 2), but these small areas only help to highlight the smoothness of the film. At higher magnification $(\times 6000)$, the feature of the film is more clearly observed (Figure 2, right) and EDXA results showed this to have similar composition to the rest of the film. It is possible that these features are a direct result of cracks forming in the underlying film being used as nucleation points for further film growth, supporting the proposition that films were deposited via an island growth mechanism.

SEM images of the zinc-gallium-oxide thin films deposited on quartz at $450{ }^{\circ} \mathrm{C}$ and annealed at $1000{ }^{\circ} \mathrm{C}$ overnight showed that they were identical in morphology to those deposited at $550{ }^{\circ} \mathrm{C}$. The films were featureless, but again after scanning large areas of the films, surface defects could be found, although EDXA analysis indicates that these areas have a similar composition to the rest of the film.

In thicker films analysed, surface defects were found to be larger in area, on closer inspection of these films (Figure 3) crystallite growth is evident as a direct result of annealing. At lower magnification $(\times 6000)$, islands of film are evident (Figure 3 , left), whilst at higher magnification $(\times 40,000)$ the microstructure is clearly crystalline, showing individual clusters that have grown and agglomerated as islands of the material, indicative of the island growth mechanism of the material (Figure 3, right).

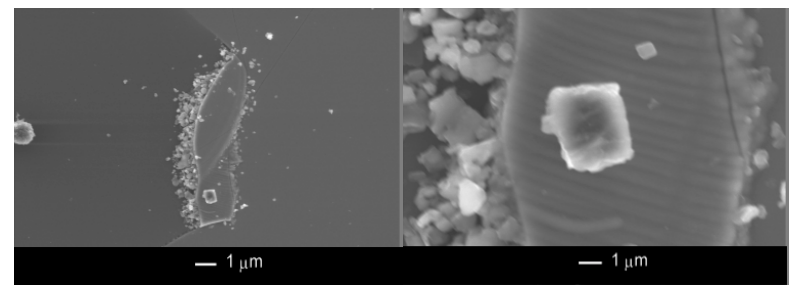

Figure. 2. SEM images of zinc-gallium-oxide film deposited at $550{ }^{\circ} \mathrm{C}$.

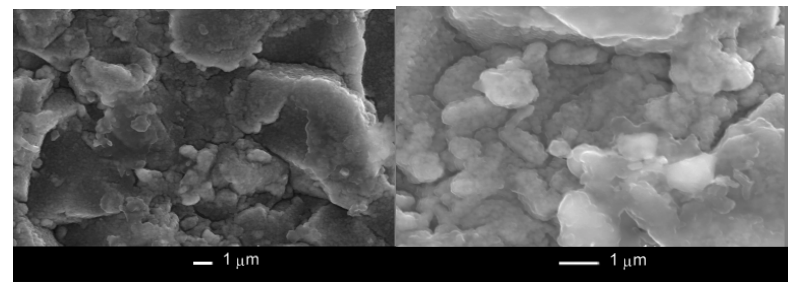

Figure 3. SEM images of features on a $\mathrm{ZnGa}_{2} \mathrm{O}_{4}$ film deposited on quartz at $450{ }^{\circ} \mathrm{C}$, annealed overnight at $1000{ }^{\circ} \mathrm{C}$.

X-ray photoelectron spectroscopy (XPS) was used to analyze the surface of the films deposited at $450{ }^{\circ} \mathrm{C}$ and annealed at $1000{ }^{\circ} \mathrm{C}$ and the whole scanning spectrum indicates the presence of the elements of $\mathrm{Ga}, \mathrm{Zn}$ and $\mathrm{O}$. The XPS of the films (Figure 4 ) reveals $G a 2 p_{1 / 2}$ and $2 p_{3 / 2}$ peaks at 1144.8 and $1117.9 \mathrm{eV}$, respectively, in a $1: 2$ ratio with an energy gap consistent with the value for the element, 26.8 $\mathrm{eV}^{[45,46]}$. The peaks at 1044.7 and $1021.6 \mathrm{eV}$ correspond to $\mathrm{Zn}$ $2 p_{1 / 2}$ and $2 p_{3 / 2}$, respectively, with the peaks in a $1: 2$ ratio again consistent with literature reports for $\mathrm{ZnGa}_{2} \mathrm{O}_{4} \cdot{ }^{[43]}$ The presence of these peaks for both gallium and zinc are consistent with those reported previously for $\mathrm{ZnGa}_{2} \mathrm{O}_{4}$. The $\mathrm{O}$ 1s peak in the XPS data can be fitted by a Gaussian distribution, centred at $530.1 \mathrm{eV}$, which is attributed to the $\mathrm{O}^{2-}$ ions in the $\mathrm{ZnGa}_{2} \mathrm{O}_{4}$ lattice. ${ }^{[4,45]}$

The O:Ga and O:Zn ratios, calculated using sensitivity factors determined from the empirical peak area and then corrected for the systems transmission function, were found to give a zinc to gallium ratio for peaks corresponding to $\mathrm{ZnGa}_{2} \mathrm{O}_{4}$ of 1:2. These results further support the formation of $\mathrm{ZnGa}_{2} \mathrm{O}_{4}$. 


\section{ChemPlusChem}
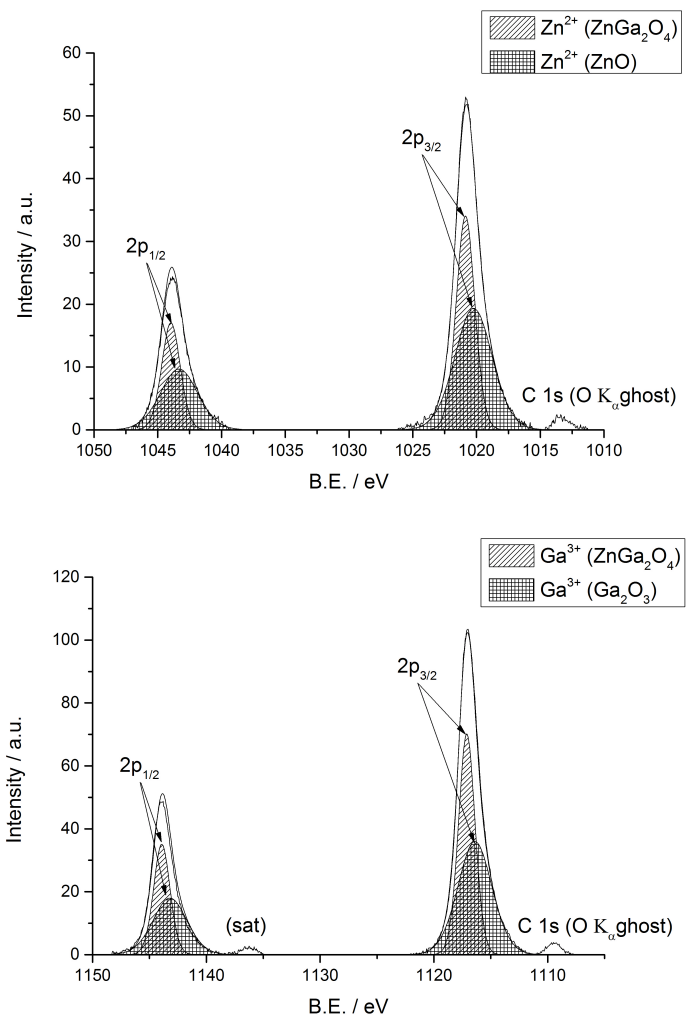

Figure 4. XPS for a film deposited at $450{ }^{\circ} \mathrm{C}$ by AACVD form the in situ reaction of $\mathrm{GaMe}_{3}, \mathrm{ZnEt}_{2}$ and excess $\mathrm{HOCH}_{2} \mathrm{CH}_{2} \mathrm{OMe}$ in toluene of: top, $\mathrm{Ga}$ $2 \mathrm{p}$ peaks, bottom, $\mathrm{Zn} 2 \mathrm{p}$ peaks.

No further impurities were observed via XPS which is in contrast to the EDXA results which showed an excess of gallium was present (1:2.6, $\mathrm{Zn:Ga)}$. Based on previous reports it is likely that at the temperatures of deposition and annealing, amorphous $\beta-\mathrm{Ga}_{2} \mathrm{O}_{3}$ as well as crystalline $\mathrm{ZnGa}_{2} \mathrm{O}_{4}$ has been formed for these films. EDXA indicated that both $\mathrm{Zn}$ and $\mathrm{Ga}$ were present in the bulk of the film and the XPS suggests that only zinc gallate exists at the surface. Therefore it is likely that the bulk of the film comprises of $\mathrm{ZnGa}_{2} \mathrm{O}_{4}$ and amorphous $\mathrm{Ga}_{2} \mathrm{O}_{3}$, which would account for the excess gallium in the EDXA result, with some surface segregation effects resulting in only zinc gallate $\left(\mathrm{ZnGa}_{2} \mathrm{O}_{4}\right)$ being present at the surface (consistent with the surface techniques of XRD and XPS) $\cdot{ }^{[19]} \mathrm{A}$ similar effect was observed for $\mathrm{ZnGa}_{2} \mathrm{O}_{4}$ films deposited by spin coating a sol-gel colloidal suspension, which resulted in a multiphasic material composed of crystallites of $\mathrm{ZnGa}_{2} \mathrm{O}_{4}$ in an amorphous matrix of zinc and gallium oxides. ${ }^{[46]}$

Transmission and reflectance measurements between 200 and $2550 \mathrm{~nm}$ showed that the films displayed minimal reflectivity $(5-10 \%)$ and were highly transparent with transparency ranges from $80 \%$ to $90 \%$ in the visible. The transmission characteristics of the deposited films were investigated using UV/vis/near IR spectrometry. All films were highly transparent with almost all having average transparencies in the region of $80 \%$.

\section{Conclusions}

AACVD of $\mathrm{ZnEt}_{2}, \mathrm{GaMe}_{3}$ and $\mathrm{HOCH}_{2} \mathrm{CH}_{2} \mathrm{OMe}$ resulted in the formation of $\mathrm{ZnGa}_{2} \mathrm{O}_{4}$, zinc gallate, films on glass. The in situ reaction of the reagents eliminates the need for the synthesis, isolation and purification of a single-source metal alkoxide precursor. The EDXA results in combination with powder XRD and XPS suggest the formation of amorphous gallium oxide and zinc gallate in the bulk of the film with surface segregation resulting in only zinc gallate at the surface. Since this is the first report of AACVD of $\mathrm{ZnGa}_{2} \mathrm{O}_{4}$ to our knowledge, it is possible that facile doping of an array of elements into these spinel systems could be facilitiated with ease, using CVD methods, furthermore, as reported in this paper all films do not require further reduction under a flow of $\mathrm{H}_{2}$ as seen in other reports. The methods described herein offer a viable low cost, low temperature route to functional spinel materials.

\section{Experimental Section}

Caution: It should be noted that $\mathrm{GaMe}_{3}$ and $\mathrm{ZnEt}_{2}$ are pyrophoric substances, which ignite spontaneously in air and the CVD of these chemicals can potentially be toxic and corrosive. All experimental should be conducted in a fume hood. Following the deposition films are air and moisture stable and are safe to handle as any reactive species leave via the reactor exhaust during the AACVD process.

General procedures - Depositions were carried out under dinitrogen (99.99\% from BOC). Precursors were placed in an AACVD glass bubbler and an aerosol mist was created using a piezoelectric device. The solvent mist was transported in a flow of cold nitrogen from the bubbler in an 8-mm gauge pipe to a horizontal bed, cold-wall reactor (internal dimensions $15 \mathrm{~cm} \times$ $5 \mathrm{~cm}$ ) fitted with a graphite block containing a Whatman cartridge heater, used to heat the glass substrate. The temperature of the substrate was monitored by a Pt-Rh thermocouple. Depositions were carried out by heating the horizontal bed reactor to the required temperature before diverting the nitrogen line through the aerosol and to the reactor. The glass substrate was $\mathrm{SiO}_{2}$, precoated (ca $50 \mathrm{~nm}$ thick $\mathrm{SiO}_{2}$ barrier layer) standard float glass (Pilkington, NSG) $15 \mathrm{~cm} \times 4 \mathrm{~cm} \times 0.3 \mathrm{~cm}$. A sheet of polished quartz $(4 \mathrm{~cm} \times 1.5$ $\mathrm{cm} \times 0.1 \mathrm{~cm}$ ) was placed on the substrate $2 \mathrm{~cm}$ from the front of the reactor to enable a subsequent annealing step at 1000 ${ }^{\circ} \mathrm{C}$. The substrates were cleaned prior to use, to remove surface grease. Two-way taps were used to divert the nitrogen carrier gas through the bubbler and the aerosol was carried into the reactor in a stream of nitrogen gas through a brass baffle to obtain a laminar flow. The total time for the deposition process was in the region of $30-90$ minutes. At the end of the deposition the nitrogen flow through the aerosol was diverted and only nitrogen passed over the substrate. The glass substrate was allowed to cool with the graphite block to less than $100{ }^{\circ} \mathrm{C}$ before it was removed. Coated substrates were handled and stored in air. Large pieces of glass (ca. $4 \mathrm{~cm} \times 2$ $\mathrm{cm}$ ) were used for $\mathrm{X}$-ray powder diffraction. The coated glass substrate was cut into ca. $1 \mathrm{~cm} \times 1 \mathrm{~cm}$ squares for subsequent 
analysis by scanning electron microscopy (SEM) and energy dispersive analysis of $\mathrm{X}$-rays (EDX).

AACVD reactions of $\mathrm{GaMe}_{3}, \mathrm{ZnEt}_{2}$ and $\mathrm{HOCH}_{2} \mathrm{CH}_{2} \mathrm{OMe}$ A large number of $A A C V D$ runs were performed in order to perfect the deposition of the $\mathrm{ZnGa}_{2} \mathrm{O}_{4}$ spinel. Throughout the work the precursor solution was generated in situ from the reaction of $\mathrm{GaMe}_{3}, \mathrm{ZnEt}_{2}$ and excess $\mathrm{HOCH}_{2} \mathrm{CH}_{2} \mathrm{OMe}$ in THF or toluene. Trimethylgallium and diethylzinc were supplied by SAFC Hitech and used without further purification. $\mathrm{HOCH}_{2} \mathrm{CH}_{2} \mathrm{OMe}$ was procured from Aldrich and was distilled, degassed and stored over molecular sieves. Excess alcohol was used in order to minimize the risk of producing partially oxidized films. The effect of the metal precursor ratio $\left(\mathrm{GaMe}_{3}: \mathrm{ZnEt}_{2}\right)$ on film composition was investigated by using different masses of precursor.

Flow rate was initially experimented with and optimised at $1 \mathrm{Lmin}^{-1}$, in addition a range of temperatures $\left(300-550{ }^{\circ} \mathrm{C}\right)$ were attempted for the deposition process. Deposition times for each experiment ranged from 60 to 90 minutes. After deposition, the bubbler was closed and the substrate allowed to cool under a flow of nitrogen. When quartz was used in the deposition process, this was added on top of the substrate before the deposition process, these were annealed for 24 hours at $1000{ }^{\circ} \mathrm{C}$. Note: when handling $\mathrm{GaMe}_{3}$ and $\mathrm{ZnEt}_{2}$ it is advised that they are cooled to $-78{ }^{\circ} \mathrm{C}$ before adding solvent, this is then allowed to warm to room temperature before deposition.

\section{Physical Measurements}

Powder X-ray diffraction (XRD) patterns were measured on a micro-focus Bruker GADDS diffractometer equipped with monochromated $\mathrm{Cu}$ Ka1 radiation $(\mathrm{Ka} 1=1.5406 \AA)$. The diffractometer used glancing incident radiation $\left(1.5^{\circ}\right)$. The samples were indexed using the GSAS program and refined using the La Bail method and were compared to database standards. EDAX was obtained on a Philips XL30ESEM instrument, and SEM on a JEOL 6301 instrument. High resolution X-ray photoemission spectra (XPS) were recorded on a Kratos Axis Ultra DLD spectrometer at the University of Nottingham, using a mono-chromated Al-Ka $(h v=1486.6 \mathrm{eV})$ $\mathrm{X}$-ray source. A standard wide scan with high resolution large areas ( 300 $\times 700$ microns) with pass energy 80 and 20 were used respectively. Binding energies were referenced to an adventitious $\mathrm{C} 1 \mathrm{~s}$ peak at $284.9 \mathrm{eV}$ (this peak is due to residual pump oil used in the XPS high vacuum system). The photoelectrons were detected using a hemispherical analyzer with channel plates and delay line detector. UV-vis-NIR spectra were recorded in the range 190-1100 nm using a Helios double beam instrument. Reflectance and transmission spectra were recorded between $300 \mathrm{~nm}$ and $2300 \mathrm{~nm}$ by a Zeiss miniature spectrometer. Reflectance measurements were standardized relative to a rhodium mirror, and transmission relative to air.

\section{Acknowledgements}

CJC and IPP thank the EPSRC for a studentship through the UCL MMMS Doctoral Training Centre (JAM) as well as the grants EP/H00064X and EP/K001515 (CEK). Pilkington NSG are thanked for funding (JAM) and glass substrates. SAFC Hitech are thanked for supplying $\mathrm{ZnEt}_{2}$ and $\mathrm{GaMe}_{3}$.

Keywords: Zinc gallate $\cdot$ zinc gallium oxide spinel $\bullet$ thin films $•$ chemical vapour deposition

[1] Xiaojun Sun, K. Maeda, M. Le Faucheur, K. Teramura, K. Domen, Appl. Cat. A, 2007, 327, 114

[2] X. Chen, H. Xue, Z. Li, L. Wu, X. Wang, X. Fu, J. Phys. Chem. C, 2008, 112, 20393.

[3] S. C. Yan, S. X. Ouyang, J. Gao, M. Yang, J. Y. Feng, X. M. Fan, L. J. Wan, Z. S. Li, J. H. Ye, Y. Zhou, Z. Zou, Angew. Chem., Int. Ed., 2010, 49, 6400.

[4] O. M. Bordun, I. Y. Kukharskyy, V. G. Bihday, J. App. Spec., 2013, 79, 997.

[5] M. Zhong, Y. Li, I. Yamada, J.-J. Delaunay, Nanoscale, 2012, 4, 1509.

[6] T. Omata, N. Ueda, K. Ueda, H. Kawazoe, Appl. Phys. Lett., 1994, 64, 1077.

[7] A. Fujishima, T. N. Rao, D. A. Tryk, J. Photochem. Photobiol., C 2000, $1,1$.

[8] N. F. Santos, A. J. S. Fernandes, L. C. Alves, N. A. Sobolev, E. Alves, K. Lorenz, F. M. Costa,. T. Monteiro, Nucl. Instrum. Methods B., 2013, 306, 195.

[9] C. Jia, W. Fan, F. Yang, X. Zhao, H. Sun, P. Li, L. Liu, Langmuir, 2013, 29, 7025.

[10] R. J. Hill, J. R. Graig, G. V. Gibbs, Phys. Chem. Minerals, 1979, 4, 317.

[11] S. Itoh, H. Toki, Y. Sato, K. Morimoto, T. Kishino, J. Electrochem. Soc., 1991, 138 (5), 1509.

[12] M. Takesada, M. Osada, T. Isobe, J. Phys. Chem. Solids, 2009, 70, 281.

[13] X. L. Duan, D. R. Yuan, L. H. Wang, F. P. Yu, X. F. Cheng, Z. Q. Liu, S. S. Yan, J. Cryst. Growth, 2006, 296, 234.

[14] M. Allix, S. Chenu, E. Veron, T. Poumeyrol, E. A. Kouadri-Boudjelthia, S. Alahrache, F. Porcher, D. Massiot, F. Fayon, Chem. Mater, 2012, $25,1600$.

[15] M. M. Can, G. H. Jaffari, S. Aksoy, S. I. Shah, T. Firat, J. Alloy. Compd., 2013, 549, 303.

[16] P. Marchand, I. A. Hassan, I. P. Parkin, C. J. Carmalt, Dalton Trans., 2013, 42, 9422.

[17] C. E. Knapp, I. Dimitri-Prassides, S. Sathasivam, I. P. Parkin, C. J. Carmalt, Chem. Plus. Chem. 2014, 122.

[18] R. Binions, C. J. Carmalt, I. P. Parkin, Meas. Sci. Technol. 2007, 18, 190.

[19] S. Basharat, C.J. Carmalt, R. Binions, R. Palgrave, I.P. Parkin, Dalton Trans. 2008, 591.

[20] R. Binions, C.J. Carmalt, I.P. Parkin, K.F.E. Pratt, G.A. Shaw, Chem. Mater. 2004, 16, 2489.

[21] S. Basharat, W. Betchley, C.J. Carmalt, S. Barnett, D.A. Tocher, H.O. Davies, Organometallics 2007, 26, 403.

[22] S. Basharat, C.J. Carmalt, S.J. King, E.S. Peters, D.A. Tocher, Dalton Trans. 2004, 3475.

[23] S. Basharat, C.J. Carmalt, R. Palgrave, S.A. Barnett, D.A. Tocher, H.O. Davies, J. Organomet. Chem. 2008, 693, 1787.

[24] D. Pugh, L. G. Bloor, I. P. Parkin, C. J. Carmalt, Chem. Eur. J. 2012, 18,6079 .

[25] D. Pugh, L. G. Bloor, S. Sathasivam, I. P. Parkin, C. J. Carmalt, Eur. J. Inorg. Chem. 2011, 1953.

[26] S. Basharat, C.J. Carmalt, S.A. Barnett, D.A. Tocher, H.O. Davies, Inorg. Chem. 2007, 46, 9473

[27] S. Elouali, L. G. Bloor, R. Binions, I. P. Parkin, C. J. Carmalt, J. A. Darr, Langmuir 2012, 28, 1879.

[28] C. E. Knapp, A. Kafizas, I. P. Parkin, C. J. Carmalt, J. Mater. Chem. 2011, 21, 12644.

[29] C. E. Knapp, G. Hyett, I. P. Parkin, C. J. Carmalt, Chem. Mater. 2011, 23, 1719 . 


\section{ChemPlusChem}

\section{Full Paper's}

[30] L. G. Bloor, J. Manzi, R. Binions, I. P. Parkin, D. Pugh, A. Afonja, C. S. Blackman, S. Sathasivam, C. J. Carmalt, Chem. Mater. 2012, 24 2864.

[31] S. Ponja, S. Sathasivam, N. Chadwick, A. Kafizas, S. M. Bawaked, A. Y. Obaid, S. Al-Thabaiti, S. N. Basahel, I. P. Parkin, C. J. Carmalt, J. Mater. Chem. A 2013, 1, 6271.

[32] E. Egerton, A.K. Sood, R. Singh, Y.R. Puri, R.F. Davis, J. Pierce, D.C. Look, T. Steiner, J. Electron. Mater., 2005, 34, 949.

[34] A.A. Hanna, S.M.A. Mousa, M.A. Sherief, G.M.J. Elkomy, J. American Science, 2010, 6, 295.

[35] T. Sei, Y. Nomura, T.J. Tsuchiya, Non-Crystalline Solids, 1997, 218 , 135.

[36] T. Minami, Y. Kuroi, S.J. Takata, Vac. Sci. Technol. A, 1996, 14, 1736

[37] C.G. Kim, W. Koh, S.-J. Ku, E.J. Nah, K.-S. Yu, Y. Kim, Y. J. Phys. IV France, 1999, 9, 853

[38] Y. Yuan, W. Du, X. Qian, J. Mater. Chem., 2012, 22, 653.

[39] J.J. Robbins, J. Esteban, C. Fry, C.A.J. Wolden, Electrochem. Soc., 2003, 150, 693.

[40] J.-H. Lee, K.-H. Ko, B.-0. Park, Journal of Crystal Growth, 2003, 247 119
[41] M: E. Fragala, G. Malandrino, M. M. Giangregorio, M. Losurdo, G. Bruno, S. Lettieri, L. S. Amato, P. Maddalena, Chemical Vapor Deposition, 2009, 15, 327.

[42] P. Nunes, D. Costa, E. Fortunato, R. Martins, Vacuum, 2002, 64, 293.

[43] A.D. Goncalves, M.R. Davolos, N. Masaki, S. Yanagida, A. Morandeira, J.R. Durrant, J.N. Freitas, A.F. Nogueira, Dalton Trans. 2008, 1487.

[44] J.F. Moulder, W.F. Sticks, P.E. Sobol, K.D. Bomben, Handbook of Xray Photoelectron Spectroscopy; Physical Electronics Inc.: USA, 1995.

[45] H.H Wang, S. Baek, J.J. Song, J. Lee, S.W. Lim, Nanotechnology, 2008, 19, 075607

[46] P. Delichere, S. Daniele, L.G. Hubert-Pfalzgraf, Surf. Sci. Spectra, 2001, 8, 303.

Received: ((will be filled in by the editorial staff))

Published online: ((will be filled in by the editorial staff)) 
ChemPlusChem

ChemPubSoc

\section{Entry for the Table of Contents}

\section{FULL PAPER}

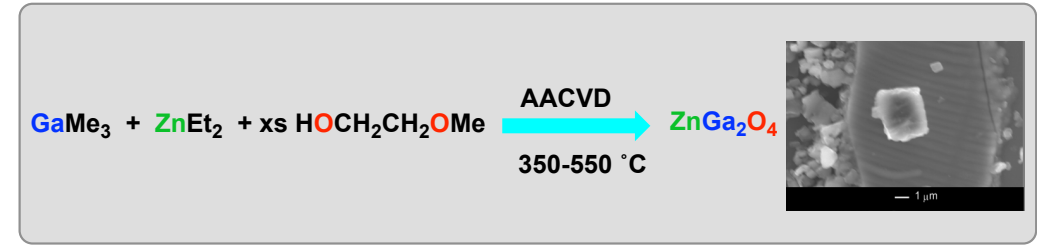

Transparent zinc gallate films have been deposited via a simple one pot solution based aerosol-assisted chemical vapour deposition (AACVD) method. AACVD of trimethylgallium, diethylzinc and the donor functionalised alcohol, $\mathrm{HOCH}_{2} \mathrm{CH}_{2} \mathrm{OMe}$, in toluene resulted in the formation of $\mathrm{ZnGa}_{2} \mathrm{O}_{4}$ films along with some amorphous $\mathrm{Ga}_{2} \mathrm{O}_{3}$. The optimum growth temperature was $450^{\circ} \mathrm{C}$.
Dr. C. E. Knapp, J. A. Manzi, Dr. A. Kafizas, Prof. I. P. Parkin and Prof. C. J. Carmalt *

Page No. - Page No.

Aerosol Assisted Chemical Vapour deposition of Transparent Zinc Gallate Films 